IFAS Extension

Healthy Snacks for Children ${ }^{1}$

Center for Science in the Public Interest ${ }^{2}$

Healthy snacks can help children get the nutrients they need to grow and play. Offering healthy snacks also can help children form lifelong healthy eating habits. Try some of these ideas!

\section{Fruits and Vegetables}

Serve fruits and vegetables often. Canned, frozen, and dried fruits store well and need little preparation. Get kids interested by letting them pick a new fruit or vegetable at the grocery store. Or let them help grow a fruit or vegetable garden. Give these a try:

Fresh fruits and vegetables

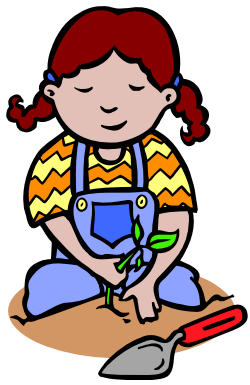
served whole, sliced, cut in half, cubed, or in wedges. Serve veggies with a lowfat salad dressing dip.

$\checkmark$ Frozen fruit

$\checkmark$ Fruit salad

$\checkmark$ Fruit cups or fruit canned in juice or light syrup

$\checkmark$ Dried fruit or fruit leathers with no added sugar

$\checkmark$ Homemade smoothies or fruit juice popsicles

$\checkmark$ Vegetables dipped in hummus, bean dip, or salad dressing

$\checkmark$ Veggie pockets in whole-wheat pita bread

\section{Healthy Grains}

Choose whole grain foods that are low in fat and sugar. Look for breads, cereals, and other grain foods that have whole wheat or another whole grain listed as the first ingredient. Here are some good choices:

Whole-grain breads, English muffins, pita, tortillas, crackers, breadsticks, or flatbreads

Whole-grain cereals

Whole-grain tortilla chips, granola, or cereal bars

Popcorn

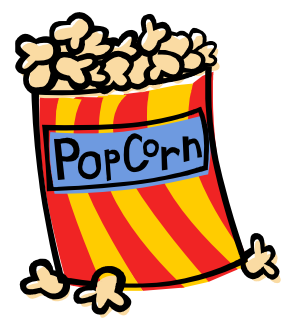

Pretzels, goldfish crackers, white bread, and other refined grains have less fiber, vitamins, and minerals than whole grains. Use whole grain foods more often. It's a good idea to make at least half of your grain food choices whole grains.

1. This document is FCS8823, one of a series of the Department of Family, Youth and Community Sciences, Florida Cooperative Extension Service, IFAS, University of Florida, Gainesville, FL 32611. First published: December 2006. Please visit the EDIS Website at http://edis.ifas.ufl.edu.

2. Adapted for use in Florida with permission from Healthy Snacks for Children, Center for Science in the Public Interest, 2006, by Jennifer Hillan, MSH, RD, LD/N, ENAFS nutrition educator, Department of Family, Youth and Community Sciences, Florida Cooperative Extension Service, Institute of Food and Agricultural Sciences, University of Florida, Gainesville, FL 32611. 


\section{Milk, Yogurt, and Cheese}

Offer children

low-fat or fat-free

snacks, such as:

$\checkmark$ Low-fat

pudding

$\checkmark$ Low-fat or fat-

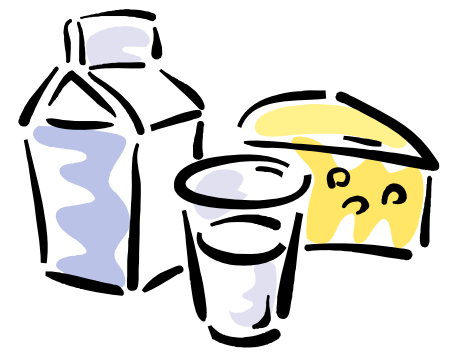

free milk

$\checkmark$ Low-fat cottage cheese

$\checkmark$ Low-fat string cheese

Cheese is high in saturated fat, so serve small portions and serve cheese with other foods like fruit, vegetables, or whole-grain crackers.

\section{Nuts and Trail Mix}

Nuts are a good source of many vitamins and minerals, but they also are high in calories. Offer small portions (a small handful) and serve them with another food, such as fruit.

To avoid a choking hazard, do NOT give whole nuts to very young children. They need to be able to chew well to handle eating whole nuts. Also, if family members have food allergies, offer only one type of nut at a time. If there is no allergic reaction, you can introduce another type of nut after about one week.

\section{Healthy Beverages}

$\checkmark$ Offer low-fat and fat-free milk instead of whole and $2 \%$ milk. Children will get the same amount of calcium, vitamin $\mathrm{D}$, and other nutrients, but not all the fat found in whole and $2 \%$ milk.

$\checkmark$ Soy and rice "milks" also are healthy choices if they are fortified with calcium and vitamin $\mathrm{D}$ (read the label).

$\checkmark$ Water is a low-cost drink that satisfies thirst without adding calories or sugars.

$\checkmark$ Calorie-free seltzer or sparkling waters are healthy choices.

$\checkmark$ Limit fruit juice to six ounces for one- to sixyear-olds and 12 ounces for seven- to eighteen-year-olds. Choose only $100 \%$ fruit juice with no added sugar or high fructose corn syrup.

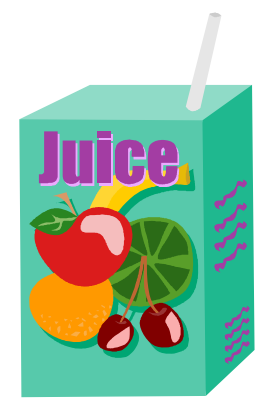

We gratefully acknowledge the Center for Science in the Public Interest for giving us permission to create this adaptation of their Healthy Snacks for Children publication. You can visit their Web site at: www.cspinet.org/nutritionpolicy.

Children under the age of two should NOT be given lowfat or fat-free milk. They need the extra fat found in whole milk to grow and develop. Fat and cholesterol both are important for brain development in babies! After age two, they can begin the move to low-fat $(1 \%)$ or fat-free milk. 